\title{
Computer Science through Concurrent Enrollment: A Strategy to Broaden Participation
}

\author{
Renee Fall (moderator) \\ College of St. Scholastica \\ St. Paul, MN \\ rfall@css.edu
}

\author{
Seth Freeman \\ Capital Community College \\ Hartford, CT \\ sfreeman@capitalcc.edu
}

\author{
Ronald I. Greenberg \\ Loyola University Chicago \\ Chicago, IL \\ rig@cs.luc.edu
}

\author{
Dan Kaiser \\ Southwest Minnesota State University \\ Marshall, MN \\ dan.kaiser@smsu.edu
}

\author{
Nigamanth Sridhar \\ Cleveland State University \\ Cleveland, $\mathrm{OH}$ \\ n.sridhar1@csuohio.edu
}

\begin{abstract}
Most U.S. states support college-readiness and access through dual enrollment, in which high school students enroll in college courses. Concurrent enrollment (CE) allows students to take college courses in their own high school, taught by high school teachers approved by the partner college. CE has positive effects on students' education, but rarely is CS available through CE. Unlike AP, CE provides college credit to students who are assessed throughout the course rather than by a single high-stakes exam/project. This panel will showcase four different types of post-secondary institutions' experiences offering CS-through-CE and discuss its potential as an entry point into CS for students underrepresented in computing, including those in urban and rural settings. Panelists will share challenges (such as teacher credentialing) and benefits of CS-through$\mathrm{CE}$. The audience will understand supports and barriers to creating CS-through-CE courses, will be provided with resources, and will crowd-source possible next steps in implementing $\mathrm{CE}$ as a model for broadening participation.
\end{abstract}

\section{CCS CONCEPTS}

- Social and professional topics $\rightarrow$ K-12 education; Accreditation; CS1.

\section{KEYWORDS}

Concurrent Enrollment; Dual Credit; Dual Enrollment; Advanced Placement; CS Education; CS Principles; Broadening Participation

\section{ACM Reference Format:}

Renee Fall (moderator), Seth Freeman, Ronald I. Greenberg, Dan Kaiser, and Nigamanth Sridhar. 2020. Computer Science through Concurrent Enrollment: A Strategy to Broaden Participation. In The 51st ACM Technical Symposium on Computer Science Education (SIGCSE '20), March 1114, 2020, Portland, OR, USA. ACM, New York, NY, USA, 2 pages. https: //doi.org/10.1145/3328778.3366981

Permission to make digital or hard copies of part or all of this work for personal or classroom use is granted without fee provided that copies are not made or distributed for profit or commercial advantage and that copies bear this notice and the full citation on the first page. Copyrights for third-party components of this work must be honored.

For all other uses, contact the owner/author(s).

SIGCSE '20, March 11-14, 2020, Portland, OR, USA

(C) 2020 Copyright held by the owner/author(s)

ACM ISBN 978-1-4503-6793-6/20/03.

https://doi.org/10.1145/3328778.3366981

\section{SUMMARY}

Nearly all 50 U.S. states sponsor programs that allow high school students to enroll in college courses to increase college readiness and decrease college cost. Such "dual enrollment" (DE) has been found to have "positive effects on students' degree attainment (college), college access and enrollment, credit accumulation, completing high school, and general academic achievement (high school)" [5]. However, computer science (CS) is rarely offered as dual enrollment. Rather, recent years have seen investment and growth in Advanced Placement (AP) CS courses in high schools, particularly the new AP CS Principles (CSP) as a breadth-first introduction to computing geared to engage students who have been underrepresented in computing (females, students with disabilities, and historically minoritized groups) [4]. However, not all schools offer AP courses, and many students shy away from AP. Between 2002 and 2010, dual enrollment grew more than $7 \%$, and about $12 \%$ in schools with majority minority enrollment and rural schools [3]. This panel will explore CS-through-CE as a pathway for underrepresented students to engage with college-level CS while in high school.

Concurrent enrollment (CE), a form of dual enrollment in which college-approved high school teachers teach college-level courses in their high schools, is an alternative to AP. Students' chances of earning college credit from an AP course rest on a single, highstakes exam and project. In addition, not all colleges grant credit for AP CS courses [1]. In contrast, CE coursework is assessed as a college course, with final grades determined by student work accumulating over a year or semester, and course success guarantees college credit. A handful of colleges and universities offer computer science through concurrent enrollment (CS-through-CE). For example, an NSF-sponsored project is exploring the barriers and supports to offering Mobile CSP as CE and examining its potential to broaden participation in computing [2].

This panel will showcase four different types of post-secondary institutions' experiences offering CS-through-CE and discuss its potential as an entry point into computer science for students underrepresented in computing, including those in urban and rural settings. Panelists will share challenges (such as teacher credentialing) and benefits of CS-through-CE. Audience participants will understand supports and barriers to creating CS-through-CE courses, will be provided with resources, and will crowd-source possible next steps in implementing CE as a model for broadening participation. 


\section{PANEL STRUCTURE}

Our moderator will begin with an introduction of the panelists, definitions, and review of research on CE (10 min.) Each panelist will share a 4-minute summary of $\mathrm{CE}$ offerings at their institution, noting which courses are taught by whom and to what students, as well as explaining what instructor credentials are required. Panelists will then respond to questions (each question limited to 6 minutes):

- What are your goals in offering CS as concurrent enrollment, and are these goals being met?

- What are the greatest challenges to offering CS as CE?

- What are some of the benefits to offering CS as CE?

The discussion (30 min.) will include Q\&A with panelists and facilitated small and large-group discussion about benefits of and challenges to offering CS-through-CE, ending with resource-sharing and ideas for next steps.

\section{SETH FREEMAN}

Capital Community College (CCC) is an urban public community college in Hartford, CT. College Career Pathways (CCP) is a statewide concurrent enrollment program common to the twelve community colleges across CT. CCP provides numerous benefits to high school students, including identifying and exploring career paths, gaining relevant technical and career skills, and earning college credit while still in high school. I have experience articulating computer science and information technology coursework and approving high school faculty to teach in our CCP program. CCC is also currently participating in an NSF CSforAll RPP project to both articulate the Mobile CSP course with high schools and train high school faculty to teach the course. I will share my experiences articulating CS courses in our CCP program, and the challenges and lessons learned in our RPP project to date. Seth Freeman is department chair of the business and technology department and professor of computer information systems at CCC.

\section{RONALD I. GREENBERG}

Loyola University Chicago is a private university with undergraduate and graduate programs and strong emphases on research, teaching, and promoting diversity. The undergraduate population of about 12,000 students includes about 275 students in the most computing-focused majors. We try to offer multiple pathways for students to enter computing majors with courses to which we map both the Computer Science Principles and Computer Science A Advanced Placement Exams. The University has a very well-developed Dual Credit Program (our local terminology for concurrent enrollment) with nearly 100 course sections of about 40 courses in 15 subjects at over 20 high schools. The computer science component, however, is small, currently consisting of a few sections of the courses for which we give credit to students with an AP score of 4 or 5 . The high school teachers and curricula are vetted by Loyola, I do a site visit for computer science courses, and students in the high school classes have the option of signing up for the Loyola class that will then appear in the usual way on a Loyola transcript. We are working to expand the number of computer science offerings, with the biggest impediment being the requirements we have for teacher credentials. Ron Greenberg is professor of computer science at Loyola, the department's undergraduate program director, and its liaison to the university's dual credit program.

\section{DAN KAISER}

Southwest Minnesota State University (SMSU) is a small, public comprehensive university based in the tradition of the liberal arts. SMSU's concurrent enrollment program is accredited by the $\mathrm{Na}-$ tional Alliance of Concurrent Enrollment Partnerships (NACEP) and has long been a leader in CE in the state of Minnesota. The mathematics program alone delivers over 13,000 credits annually through CE. By offering the Mobile CSP curriculum through concurrent enrollment, we believe we can increase participation in computing from students in rural high schools especially among female students and students from underrepresented minorities. Dan Kaiser is professor of computer science and chair of the mathematics and computer science department.

\section{NIGAMANTH SRIDHAR}

Cleveland State University (CSU) is a comprehensive public university offering baccalaureate, masters, and doctoral degrees. The state of Ohio, through its College Credit Plus (CCP) program allows students in high school to enroll in college courses and earn college credit through dual enrollment. CSU has been offering teacher professional development for the CS Principles course since 2013, with funding from two NSF grants. Over the last six years, we have worked with nearly 100 teachers across the state of Ohio. In the first year of our teacher professional development, the AP test had not yet launched, and as such, we created a dual enrollment opportunity for students working with our teachers. Given the success of our pilot offering, we have continued to provide the same opportunity in subsequent years as well. Students enroll in special sections of the CIS 151 Invitation to Computing course, and when they successfully complete the CS Principles course in high school, they get college transcript credit for CIS 151 at CSU. Nigamanth Sridhar is professor of computer science at CSU. He served as PI for a CE21 CS10K project from 2013 to 2017, and is now serving as PI on a CSforAll RPP project.

\section{ACKNOWLEDGMENTS}

This material is based upon work supported by the National Science Foundation under grant numbers 1837723, 1836990, 1836983, 1339270, 1738607, and 1738691.

\section{REFERENCES}

[1] Crystal Furman, Owen Astrachan, Daniel D. Garcia, David Musicant, and Jennifer Rosato. 2019. CS Principles Higher Education Pathways. In SIGCSE '19. Association for Computing Machinery, 498-499.

[2] Mobile CSP. 2019. Concurrent Enrollment. http://www.mobile-csp.org/ce accessed 8/26/19. (2019).

[3] National Alliance for Concurrent Enrollment Partnerships. [n. d.]. Fast Facts about Dual and Concurrent Enrollment. http://www.nacep.org/resource-center/ fast-fact-on-dual-and-concurrent-enrollment accessed 10/16/19. ([n. d.]).

[4] National Science Foundation. 2015. College Board and NSF expand partnership to bring computer science to high schools across the U.S. News Release 15-060 https://www.nsf.gov/news/news_summ.jsp?cntn_id=135335. (June 2015).

[5] What Works Clearing House of the Institute of Education Sciences in the U.S. Department of Education. 2017. WWC Intervention Report: Dual Enrollment Programs. https://ies.ed.gov/ncee/wwc/Docs/InterventionReports/wwc_dual_ enrollment_022817.pdf accessed 8/26/19. (Feb. 2017). 